\section{Focal dystonia, tremor and myokymic discharges secondary to electrical injury}

\author{
Konstantina G. Yiannopoulou,' \\ Theodoros Avramidis, ${ }^{2}$ Roxani Divari, \\ Alexandros Papadimitriou ${ }^{3}$ \\ 'Department of Neurology, Laiko General \\ Hospital, Athens, Greece; \\ 2Department of Neurology, Red Cross \\ Hospital, Athens, Greece; \\ ${ }^{3}$ Department of Neurology, University of \\ Thessalia, Larissa, Greece
}

\begin{abstract}
We describe the case of a male patient who developed electromyographically confirmed myokymia, dystonia and tremor and clinically confirmed focal dystonia and tremor, secondary to electrical injury. Dystonia is a rare complication of electrical injury. Myokymic discharges secondary to electrical injury are previously unreported. Dystonia and tremor EMG findings were present not only at the clinically affected muscles of the lower limb but also at the clinically unaffected upper limb muscles. This is the first case report to link myokymia as a secondary complication of an electrical injury.
\end{abstract}

\section{Introduction}

Electrical injury as a cause of movement disorder is rare and is even less frequent as a cause of dystonia. ${ }^{1}$ Electrical injury as a cause of myokymic discharges has not been previously reported. ${ }^{2}$ We describe the case of a patient who developed electromyographically confirmed myokymia, dystonia and tremor and clinically confirmed focal dystonia and tremor, secondary to electrical injury.

\section{Case Report}

A 29-year old male was referred to the emergency room because of electrocution. He had grasped one end of a live electrical cable with his right hand, he received a severe electrical shock throwing him 2 meters backward, he lost consciousness without seizures, according to witnesses, and immediately afterwards he reported limited motion and numbness of the right extremities. An emergency room evaluation that day found no objective abnormality apart from two small electrical burns on his right hand and foot.
Twenty days later, neurological evaluation revealed very limited voluntary and passive movement of the right leg which caused an inability to flex the knee. Both voluntary and passive movements resulted in excruciating pain and tremor of the right lower limb. Examination revealed an intact mental status. Cranial nerves were intact. Motor examination of the other 3 limbs was normal.

He received diazepam and carbamazepine with no response. Botulinum toxin A procedure was considered painful and was not tolerated by the patient.

Three years later his right leg was markedly extended at the knee and every attempt to flex it caused coarse tremor and painful muscle contractions of the whole limb. Atrophy of the right quadriceps was noticed. He was trying to walk with the leg always extended in order to avoid tremor and pain. His situation remained unchanged throughout all these years, but he did not stop working as an office clerk.

He had no previous medical problems. There was no history of head trauma, systemic diseases, nor exposure to neuroleptic drugs. Family history of movement disorders was also negative.

Routine laboratory tests, brain and spinal magnetic resonance imaging (MRI) were unremarkable.

Nerve conduction studies were normal.

EMG recordings did not show neuropathic or myopathic changes but did reveal that:

a) knee flexion produced continuous muscle fiber activity of high frequency, simultaneously in agonist and antagonist muscles of the right limbs. At the same time, a painful lower limb muscle spasm was observed. The above patterns, indicative of dystonia, were stable for several minutes; ${ }^{1}$

b) immediately afterwards, a $10 \mathrm{~Hz}$ bursting pattern of motor unit action potentials with high amplitude and separated by relative silence was observed; it was produced in an alternating fashion between flexors and extensors of the right upper and lower extremity (Figure 1a). This activity with tremor morphology ${ }^{1}$ was accompanied by a high range tremor of 3-4 minutes duration only in the lower-right extremity;

c) another spontaneous activity, indicative of myokymic discharges ${ }^{2}$ was observed at rest in the right deltoid (Figure 1b), but also in the supraspinatus, trapezius and paraspinal muscles, consisting of grouped motor potentials firing at $8 \mathrm{~Hz}$ continuously with $2-4$ units within a burst.

Distraction with physical (contralateral finger tapping) or mental activities (counting, singing) did not alter any of the above described activities. The same EMG patterns were reproduced in a stereotyped manner by repeating the flexion maneuver at the knee.

There was no abnormal activity seen in the left extremities.
Correspondence: Konstantina G. Yiannopoulou, Vas. Tsounia 12A, 11526, Maroussi, Athens, Greece. E-mail: ekati2@otenet.gr

Key words: focal dystonia, tremor, myokymic discharges, electrical injury

Received for publication: 28 January 2009.

Revision received: 19 March 2009.

Accepted for publication: 24 April 2009.

This work is licensed under a Creative Commons Attribution 3.0 License (by-nc 3.0)

(C) Copyright K.G. Yiannopoulou et al., 2009

Licensee PAGEPress, Italy

Neurology International 2009; 1:e2

doi:10.4081/ni.2009.e2

\section{Discussion}

A PubMed search revealed only 10 cases of dystonia and/or tremor (Table 1) secondary to electrical injury. Only one of them is described exclusively as tremor and another as tremor and dystonia simultaneously. The 8 remaining cases are reported to suffer exclusively from dystonia. Our case is the only one with dystonia, tremor and myokymia coexistence, and the first one that presents myokymia as secondary complication of an electrical injury. Additionally, it is the only case with lower limb involvement. The previous reports include lingual involvement (2 cases), upper limb involvement (5 cases) and torticollis ( 2 cases). It is also interesting that dystonia and tremor EMG findings in our patient were present not only at the clinically affected muscles of the lower limb but also at the clinically unaffected ipsilateral upper limb muscles. EMG findings in the previous cases are reported to be present only in the clinically affected part of the body.

Electrical injury occurs when a portion of the body completes an electrical circuit. Damage occurs as a result of tissue sensitivity to thermal injury and electroporation, a term describing non-thermal damage to cell membranes as a result of electricity. ${ }^{3}$ Electrical injury can result in damage to both the peripheral and central nervous system. ${ }^{4,5}$ Several different types of movement disorders after electrocution have been reported, including torticollis, limb and lingual dystonia, tremor and Parkinsonism. ${ }^{1,6-13}$

Dystonia is a rare complication of electrical injury: only 8 cases of dystonia secondary to electrical injury have been published, ${ }^{1,6-9,12,13}$ while in two large studies with a total of 272 cases of electrical injury, no patient developed dystonia. ${ }^{14,15}$ The pathophysiology of electrically induced dystonia remains highly speculative but is widely considered to be a type of trauma-induced movement disorder. ${ }^{9}$ Posttraumatic dystonia occurs after both central 




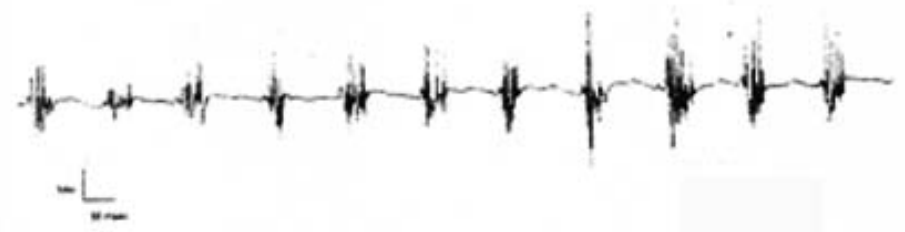

b
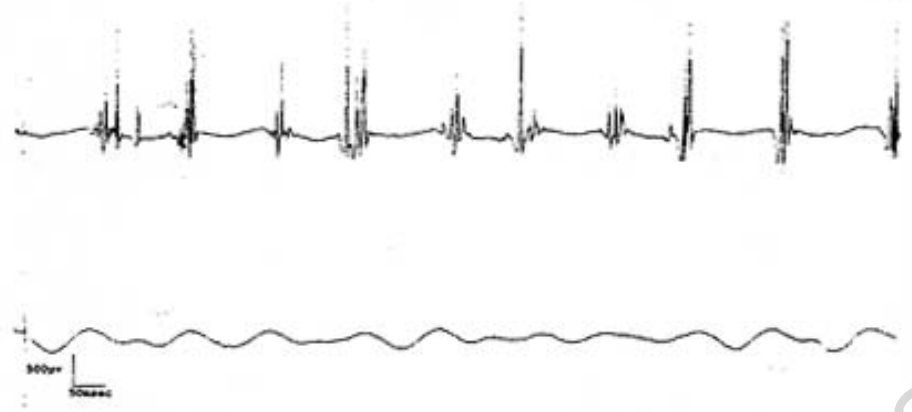

Figure 1. (a) EMG-right arm: motor unit grouping with a frequency of $10 \mathrm{~Hz}$ in an alternating pattern between flexors and extensors (tremor). (b) EMG-right arm: spontaneous discharges firing at $8 \mathrm{~Hz}$ with $2-4$ units within a burst (myokymic discharges) in the right deltoid muscle (top recording). No findings in the left deltoid muscle (bottom recording).

Table 1. Dystonia or/and tremor after electrical injury in the literature.

\begin{tabular}{|c|c|c|c|}
\hline Article & $\begin{array}{l}\text { Movement } \\
\text { disorder }\end{array}$ & $\begin{array}{l}\text { Number of } \\
\text { cases reported }\end{array}$ & $\begin{array}{l}\text { Special } \\
\text { features }\end{array}$ \\
\hline $\begin{array}{l}\text { Torticollis after } \\
\text { electrocution }\end{array}$ & Dystonia & 1 & $\begin{array}{l}\text { Torticollis/responded to botulinum } \\
\text { toxin injections }\end{array}$ \\
\hline $\begin{array}{l}\text { Limb dystonia following } \\
\text { electrical injury? }\end{array}$ & Dystonia & 3 & $\begin{array}{l}\text { Upper extremity/botulinum toxin } \\
\text { injections, in two of the patients, } \\
\text { mainly improved passive movements }\end{array}$ \\
\hline $\begin{array}{l}\text { Case of torticollis occurring } \\
\text { following electrical injury }\end{array}$ & $\begin{array}{l}\text { Dystonia } \\
\text { tremor }\end{array}$ & 1 & $\begin{array}{l}\text { Torticollis/responded to botulinum } \\
\text { toxin injections }\end{array}$ \\
\hline $\begin{array}{l}\text { Dystonia secondary to } \\
\text { electrical injury: surface } \\
\text { electromyographic evaluation } \\
\text { and implications for the } \\
\text { organicity of the condition }\end{array}$ & $\begin{array}{l}\text { Dystonia } \\
\text { tremor }\end{array}$ & 1 & $\begin{array}{l}\text { Upper extremity/some improvement } \\
\text { with botulinum toxin/finally amputation } \\
\text { of the arm because of the pain }\end{array}$ \\
\hline $\begin{array}{l}\text { Lingual dystonia } \\
\text { following electrical injury }\end{array}$ & Dystonia & 1 & \\
\hline $\begin{array}{l}\text { Focal lingual dystonia, urinary } \\
\text { incontinence, and sensory } \\
\text { deficits secondary to low } \\
\text { voltage electrocution: case } \\
\text { report and literature review }{ }^{13}\end{array}$ & Dystonia & 1 & $\begin{array}{l}\text { Lingual dystonia/resolved } \\
\text { with botulinum toxin injections }\end{array}$ \\
\hline $\begin{array}{l}\text { Tongue tremor in a patient } \\
\text { with coma after } \\
\text { electrical injury }{ }^{11}\end{array}$ & Tremor & 1 & Tongue tremor/transient/coma \\
\hline $\begin{array}{l}\text { Segmental dystonia following } \\
\text { electrocution in childhood }{ }^{12}\end{array}$ & Dystonia & 1 & Upper extremity \\
\hline
\end{tabular}

and peripheral lesions. Some researchers have postulated an underlying genetic predisposition, previous neural damage, or prior drug exposure. Pathophysiological theories advocate direct damage to the nervous system, as well as a variety of delayed indirect effects, including aberrant neuronal sprouting, denervation supersensitivity, ephaptic transmission, and oxidative reactions. Proposed criteria for a peripherally induced movement disorder are: (a) sufficient severity of the injury, (b) anatomic relationship between the injury site and the site of onset of the movement disorder and (c) a latent period of less than one year between the injury and the subsequent disease..$^{16}$ Our case fulfills these criteria in that our patient suffered a severe electrical injury, the latency between the injury and the onset of symptoms was 20 days, and the symptomatic leg was the leg which had received the injury. Although a diagnosis of psychogenic dystonia was considered, the stereotyped nature of the movement disorder and lack of variability on clinical and EMG evaluation support an organic disorder that was temporally-related to an electrical injury. The patient was never witnessed to be free of symptoms when left alone, despite having this problem for many years. There was no inconsistency in his disorder, nor did we feel there was incongruity with a diagnosis of symptomatic, organic dystonia. He underwent repetitive EMG studies, with reproducibility and a lack of variability or distraction. There were no other neurological signs suggesting psychogenicity, nor any somatizations or psychiatric disturbances.

Myokymic discharges secondary to electrical injury, have not, to our knowledge, been reported. Other causes of focal myokymia including Guillain-Barré syndrome, multiple sclerosis, radiation plexopathy, pontine tumors, meningoradiculitis, syringobulbia and hypothyroidism were ruled out. ${ }^{2,17-18}$ Since electrical injury can affect both the upper and lower motor neurons,${ }^{5}$ it seems to be the most likely origin of these EMG-recorded myokymic discharges. We suggest that the local myokymic discharges in our patient were produced by a mechanism similar to that of irradiation-induced cases,${ }^{18}$ since this is the only external triggering factor correlated to the local form of this spontaneous activity. Myokymia is a disorder of the motor unit. Its underlying cause probably involves a biochemical alteration of the microenvironment or the membrane of the motor axon. In a number of instances, abnormalities of voltage gated $\mathrm{K}^{+}$channels (VGKC) have been documented. $^{2}$ The source of generation of myokymic discharge (the ectopic generator) may be at one or more lesioned segments on the motor axon, may be further supported by ephaptic transmission or antidromic stimulation mechanisms and with the nature of the 
underlying disease process. Although radiation is often an associated cause for myokymic discharges, other factors that can irritate the motor axon and produce myokymia include demyelination, autoimmune processes, genetic determination, toxic effects, ischemia, hypoxia, and edema. ${ }^{2}$ Myokymic discharges are thought to represent axonal hyperexcitability, either due to spontaneous depolarization or to ephaptic transmission from surrounding nerves. The discharges are short bursts of single motor unit action potentials at individual discharge frequencies of $5-150 \mathrm{~Hz}$ that can occur in isolation or as multiplets. Burst durations typically range from 100 to 1,000 milliseconds. Group discharge frequencies usually occur between 1 and $5 \mathrm{~Hz}$ but may be slower and may also be variable at times. When continuous, the group discharge frequency is often dependent on the length of the burst duration, with longer bursts firing less often. ${ }^{19}$

Our case is the only one with dystonia, tremor and myokymia coexistence and the first one that presents myokymia as a secondary complication of an electrical injury. Additionally, it is the only case with lower limb dystonia and tremor after electrocution. It is also interesting, that dystonia and tremor EMG findings in our patient were present not only at the clinically affected muscles of the lower limb but also at the clinically unaffected ipsilateral upper limb muscles.

\section{References}

1. Adler CH, Caviness JN. Dystonia secondary to electrical injury: surface electromyographic evaluation and implications for the organicity of the condition. Neuro Sci 1997;148:187-92.

2. Gutmann L, Gutmann L. Myokymia and neuromyotonia 2004. Neuro 2004;251:13842.

3. Chen W, Lee RC. Evidence for electrical shock-induced conformation damage of voltage-gated ionic channels. Ann NY Acad Sci 2004;720:124-35.

4. Wilbourn AJ. Peripheral nerve disorders in electrical and lightning injuries. Semin Neurol 1995;15:241-55.

5. Cherington M. Central nervous system complications of lightning and electrical injuries. Semin of Neurol 1995;15: 233-40.

6. Colosimo C, Kocen RS, Powell M, et al. Torticollis after electrocution. Mov Disord 1993;18: 117-8.

7. Tarsy D, Sudarsky L, Charness E. Limb dystonia following electrical injury. Mov Disord 1994;9:230-2.

8. Boonkongchuen P, Lees A. Case of torticollis following electrical injury. Mov Disord 1996;11:109-10.

9. Ondo W. Lingual Dystonia following electrical injury. Mov Disord 1997;12:253.

10. Morris HR, Moriabadi NF, Lees AJ, et al. Parkinsonism following electrical injury to the hand. Mov Disord 1998;13:600-2.

11. Lin K, Lin J, Piovesan EJ, et al. Tongue tremor in a patient with coma after electrical injury. Mov Disord 2003;18:834-6.

12. Lim EC, Seet RC. Segmental dystonia following electrocution in childhood. Neurol Sci 2007;28:38-41.

13. Baskerville JR, McAninch SA. Focal lingual dystonia, urinary incontinence, and sensory deficits secondary to low voltage electrocution: case report and literature review. Emerg Med J 2002;19:368-71

14. Butler ED, Gant TD. Electrical injuries, with special reference to the upper extremities: A review of 182 cases. Am J Surg 1977;134:95-101.

15. Grube BJ, Heimbach DM, Engrav LH, Copass MK. Neurologic consequences of electrical burns. J Trauma 1990;30:254-8.

16. Jankovic J. Post-traumatic movement disorders: central and peripheral mechanisms. Neurology 1994;44:2006-14.

17. Lo YL, Ho SC, Koh LK, Khoo DH. EMG myokymia as a cause of ptosis in hypothyroidism. Eur Neurol 2003;10: 87-90.

18. Harper MC, Thomas JE, Cascino TL, Litchy WJ. Distinction between neoplastic and radiation-induced brachial plexopathy, with emphasis on the role of EMG. Neurology 1989;39:502-6.

19. Richardson RC, Weiss MD. Unilateral myokymia of the tongue after radiation therapy for cervical nodal melanoma. J Clin Neuromuscul Dis 2009;10:122-5. 